\title{
Growth and Carbon Assimilation in Potato Plants as Affected by Light Fluctuations
}

\author{
Weixing Cao and Theodore W. Tibbitts \\ Department of Horticulture, University of Wisconsin, Madison, WI 53706
}

Additional index words. Solanum tuberosum, variable light, controlled environment

The fact that plants often experience variable lighting has stimulated research on the responses of leaf photosynthesis and stomatal conductance to short-term light fluctuations (Knapp and Smith 1990; Stoop et al., 1990, 1991). However, this research has involved study of PPF fluctuations only over short periods, and no long-term experiments have been conducted under alternating PPF fluctuations to evaluate their effects on $\mathrm{CO}_{2}$ assimilation and dry-matter accumulation. We studied whether variable light would affect potato (Solanum tuberosum L.) plant growth similarly to constant light kept at the same average PPF in a controlled environment.

Two experiments were conducted in walk-in growth rooms at the Biotron, Univ. of Wisconsin, Madison. We used potato because it is being used in a study to optimize growth conditions for its use as a food source for humans in space. 'Norland', 'Russet Burbank', 'Denali', and 'Kennebec' were selected to obtain a broad genetic representation. Plants were raised from micropropagated stem cuttings (Wheeler et al., 1991), and uniform single plantlets were transplanted into the centers of 8-liter plastic pots containing 1 commercial peat : 1 vermiculite mix (v/v). Plants were watered to excess four times daily with a complete nutrient solution (Hammer et al., 1978). In each PPF treatment, the cultivars were arranged as a randomized complete block design with five replications.

In Expt. 1, PPF was alternated between 300 and $500 \mu \mathrm{mol} \cdot \mathrm{m}^{-2} \cdot \mathrm{s}^{-1}$ every $30 \mathrm{~min}$ in one growth room and kept constant at 400 $\mu \mathrm{mol} \cdot \mathrm{m}^{-2} \cdot \mathrm{s}^{-1}$ in a separate growth room. In Expt. 2, PPF levels were the same, but the variable PPF was alternated every 5 min and the two treatments were switched to the opposite growth rooms. PPF under variable lighting was adjusted by switching some bulbs on and off. The lamps reached stable state within $5 \mathrm{sec}$ after each PPF alternation. The PPFs used were selected so that the highest level would be below the saturation level for potatoes, yet all levels would be high enough to

Received for publication 25 Sept. 1992. Accepted for publication 16 Feb. 1993. Supported by the College of Agricultural and Life Sciences, Univ. of Wisconsin, Madison, and National Aeronautics and Space Administration grant NCC-2-301. The cost of publishing this paper was defrayed in part by the payment of page charges. Under postal regulations, this paper therefore must be hereby marked advertisement solely to indicate this fact. permit vigorous plant growth (Wheeler et al., 1991).

The PPF was provided by cool-white, fluorescent lamps for $12 \mathrm{~h}$. During the growth periods at the top of the canopy, PPF was 305 \pm 9 and $508 \pm 17$ (variable) and $404 \pm 12$ $\mu \mathrm{mol} \cdot \mathrm{m}^{-2} \cdot \mathrm{s}^{-1}$ (constant) in Expt. 1 , and $297 \pm$ 12 and $507 \pm 15$ (variable) and $405 \pm 13$ $\mu \mathrm{mol} \cdot \mathrm{m}^{-2} \cdot \mathrm{s}^{-1}$ (constant) in Expt. 2. Temperature and relative humidity (RH) were monitored by computer; average levels were 20.0/ $16.5 \pm 0.4 \mathrm{C}$ (light/dark) and $70 \% \pm 1 \% \mathrm{RH}$ in Expt. 1, and 20.0/16.5 $\pm 0.3 \mathrm{C}$ and $70 \% \pm 2 \%$ $\mathrm{RH}$ in Expt. 2. Carbon dioxide levels were ambient at $\approx 350 \mu l \cdot$ liter $^{-1}$

In each experiment, $\mathrm{CO}_{2}$ assimilation rates and stomatal conductance of leaves were determined in situ during the middle of the light period 29 and 34 days after transplanting using a portable photosynthesis system (model LI-6000; LI-COR, Lincoln, Neb.). Four replicate plants of 'Norland' and 'Russet Burbank' were evaluated. Measurements were taken on each plant's terminal leaflets of the fourth and fifth leaves $>2 \mathrm{~cm}$ long on the main stem. Under variable light, measurements were taken at least 2 min after each PPF fluctuation.

Plants were harvested 35 days after being transplanted in both experiments. Leaves were separated from the stems, and the area of green leaves was measured on a leaf area meter (model LI-3100; LI-COR). All plant material was oven-dried at $70 \mathrm{C}$ for 2 days and dry weights were determined. The two PPF cycling periods were assumed to be duplicated experiment runs for the variable light treatment so that an analysis of variance (ANOVA) could be conducted with variable and constant PPF treatments in two randomized blocks. Also, the data were reported as pooled averages, since individual ANOVAs did not indicate a significant PPF effect with each of the cultivars.

Plant growth measured as total and tuber dry weights and leaf area per plant was consistently, although only slightly, lower under 300 and 500 than under $400 \mu \mathrm{mol} \cdot \mathrm{m}^{-2} \cdot \mathrm{s}^{-1}$ in both experiments, whether the variable PPF was alternated every 30 or $5 \mathrm{~min}$. Averaged over the experiments, variable PPF reduced total and tuber dry weight by $6 \%$ and leaf area by $5 \%$ compared to constant PPF (Table 1). These differences, however, were significant only at $P \geq 0.08$ at 35 days after transplanting.

The decreased plant growth under variable PPF was confirmed by $\mathrm{CO}_{2}$ assimilation re-
Table 1. Average plant and tuber dry weight and leaf area of potatoes grown under variable and constant photosynthetic photon flux (PPF). PPFs of 300 and $500 \mu \mathrm{mol} \cdot \mathrm{m}^{-2} \cdot \mathrm{s}^{-1}$ were alternated every $30 \mathrm{~min}$ in Expt. 1 and every $5 \mathrm{~min}$ in Expt. 2.

\begin{tabular}{|c|c|c|c|}
\hline $\begin{array}{l}\text { PPF } \\
\left(\mu \mathrm{mol} \cdot \mathrm{m}^{-2} \cdot \mathrm{s}^{-1}\right)\end{array}$ & $\begin{array}{c}\text { Plant dry } \\
\text { wt (g) }\end{array}$ & $\begin{array}{c}\text { Tuber dry } \\
\text { wt (g) }\end{array}$ & $\begin{array}{c}\text { Leaf area } \\
\left(\mathrm{cm}^{2},\right. \\
1000 \mathrm{~s})\end{array}$ \\
\hline \multicolumn{4}{|c|}{ Expt. 1} \\
\hline 300 and 500 & $16.1^{z}$ & 4.7 & 3.0 \\
\hline 400 & 17.2 & 5.0 & 3.1 \\
\hline \multicolumn{4}{|c|}{ Expt. 2} \\
\hline 300 and 500 & 18.8 & 6.1 & 3.6 \\
\hline 400 & 20.2 & 6.5 & 3.8 \\
\hline
\end{tabular}

sults. The $\mathrm{CO}_{2}$ assimilation rates in leaves increased at 500 and decreased at $300 \mathrm{com}$ pared to $400 \mu \mathrm{mol} \cdot \mathrm{m}^{-2} \cdot \mathrm{s}^{-1}$. The increase in photosynthesis was slightly less from 400 to 500 than it was from 300 to $400 \mu \mathrm{mol} \cdot \mathrm{m}^{-2} \cdot \mathrm{s}^{-1}$, atypical response of photosynthesis to unsaturated PPF. Thus, leaf $\mathrm{CO}_{2}$ assimilation rates under variable $\mathrm{PPF}$ averaged $\approx 2 \%$ lower than under constant PPF in both experiments. The $2 \%$ decrease in leaf carbon assimilation rate and $5 \%$ decrease in leaf area may account for the $6 \%$ reduction in whole-plant carbon accumulation. Also, stomatal conductance was similar for PPF levels under variable and constant light; this result suggests a lack of stomatal response to PPF fluctuations under well-watered conditions and is consistent with an observation in chrysanthemums [Dendranthema $\times$ grandiflorum (Ramat.) Kitamura] (Stoop et al., 1991).

The results indicate that variable PPF has no advantage over constant PPF for potato growth in controlled environments. The data also imply that, in the field and greenhouse under varying light, PPF averaged over a certain period may slightly overestimate drymatter production. However, light fluctuations caused outdoors by sun, clouds, and wind (Pearcy et al., 1990) differ from those we studied.

\section{Literature Cited}

Hammer, P.A., T.W. Tibbitts, R.W. Langhans, and J.C. McFarlane. 1978. Baseline growth studies of 'Grand Rapids' lettuce in controlled environments. J. Amer. Soc. Hort. Sci. 103:649-655.

Knapp, A.K. and W.K. Smith. 1990. Stomatal and photosynthetic responses to variable sunlight. Physiol. Plant. 78:160-165.

Pearcy, R.W., J.S. Roden, and J.A. Gamon. 1990 Sunflecks dynamics in relation to canopy structure in a soybean [Glycine max (L.) Merr.] canopy. Agr. Forest Meteorol. 52: 359-372.

Stoop, J.M., M.M. Peet, D.H. Willits, and P.V. Nelson. 1990. Photosynthetic dynamics in chrysanthemum in response to single step increases and decreases in photon flux density. Plant Physiol. 94:46-53.

Stoop, J.M., D.H. Willits, M.M. Peet, and P.V Nelson. 1991. Carbon gain and photosynthetic response of chrysanthemum to photosynthetic photon flux density cycles. Plant Physiol. 96:529-536.

Wheeler, R.M., T.W. Tibbitts, and A.H. Fitzpatrick. 1991. Carbon dioxide effects on potato growth under different photoperiods and irradiance. Crop Sci. 31:1209-1213. 